\title{
Organization of Hindlimb Muscle Afferent Projections to Lumbosacral Motoneurons in the Chick Embryo
}

\author{
Matt T. Lee ${ }^{1, a}$ and Michael J. O'Donovan ${ }^{1,2}$ \\ 'Department of Physiology and Biophysics, University of lowa, lowa City, lowa 52242 and ${ }^{2}$ The Laboratory of Neural \\ Control, National Institute of Neurological Disease and Stroke, NIH, Bethesda, Maryland 20892
}

\begin{abstract}
We have examined the organization of muscle afferent projections to motoneurons in the lumbosacral spinal cord of chick embryos between stage 37 , when muscle afferents first reach the motor nucleus, and stage 44, which is just before hatching. Connectivity between afferents and motoneurons was assessed by stimulating individual muscle nerves and recording the resulting motoneuron synaptic potentials intracellularly or electrotonically from other muscle nerves. Most of the recordings were made in the presence of DL-2-amino-5-phosphonovaleric acid (APV), picrotoxin, and strychnine to block long-latency excitatory and inhibitory pathways.
\end{abstract}

Activation of muscle afferents evoked slow, positive potentials in muscle nerves but not in cutaneous nerves. These potentials were abolished in $0 \mathrm{mM} \mathrm{Ca}^{2+}, 2 \mathrm{mM} \mathrm{Mn}^{2+}$ solutions, indicating that they were generated by the action of chemical synapses. The muscle nerve recordings revealed a widespread pattern of excitatory connections between afferents and motoneurons innervating six different thigh muscles, which were not organized according to synergist-antagonist relationships. This pattern of connectivity was confirmed using intracellular recording from identified motoneurons, which allowed the latency of the responses to be determined. Short-latency potentials in motoneurons were produced by activation of homonymous afferents and the heteronymous afferents innervating the hip flexors sartorius and anterior iliotibialis. Stimulation of anterior iliotibialis afferents also resulted in some short-latency excitatory postsynaptic potentials (EPSPs) in motoneurons innervating the knee extensor femorotibialis, though other connections were of longer latency. Afferents from the adductor, a hip extensor, did not evoke short-latency EPSPs in any of these three types of motoneurons. Short-latency, but not long-latency EPSPs, persisted during repetitive stimulation at $5 \mathrm{~Hz}$, suggesting that they were mediated monosynaptically. Longlatency, fatigue-sensitive potentials were maintained in the presence of APV, picrotoxin, and strychnine, suggesting that polysynaptic pathways utilize non-NMDA receptors as well

\footnotetext{
Received Oct. 29, 1990; revised Mar. 13, 1991; accepted Mar. 19, 1991.

Part of this work was supported by NIH Grant NS22559 to M.J.O., who received a National Institute of Neurological Disease and Stroke RCDA NS01246. Thanks are due to Dr. Bob Burke for critical comments on the manuscript and to Dr. Carolyn Smith for helpful discussions.

Correspondence should be addressed to Michael O'Donovan, I aboratory of Neural Control, Room 5a-29, Building 36, National Institute of Neurological Disease and Stroke, NIH, Bethesda, MD 20892

a Present address: Biology Department, Carleton College, One North College Street, Northfield, MN 55057.

Copyright (C) 1991 Society for Neuroscience $0270-6474 / 91 / 112564-10 \$ 03.00 / 0$
}

as NMDA receptors. We found no difference in the pattern of inputs to femorotibialis motoneurons between stage 3739 and near hatching at stage 44 , suggesting muscle afferent projections to these motoneurons are correct at stage 37 , when the afferents first reach the lateral motor column in substantial numbers.

The chick embryo has been recognized for many years as an excellent model for developmental studies of neural connectivity (Windle and Orr, 1934; Windle and Baxter, 1936; Hamburger, 1976; Lance-Jones and Landmesser, 1981; Eide et al., 1982; Honig, 1982; Scott, 1982; Landmesser and O'Donovan, 1984; Okado and Oppenheim, 1985; Lee et al., 1988; Davis et al., 1989). Despite its popularity, there have been surprisingly few detailed electrophysiological investigations of neural pathway formation (Eide et al., 1982). Recently, we have attempted to redress this situation by analyzing the formation of sensorimotor connections using an isolated preparation of the chick spinal cord (Lee et al., 1988). We chose to examine the development of muscle afferent projections in the chick because of the experimental convenience of this system. In a previous report, we showed that synaptic transmission between muscle afferents and motoneurons is mediated by an excitatory amino acid acting on non-NMDA postsynaptic receptors on motoneurons (Lee et al., 1988). That study also revealed that hindlimb muscle afferents form their initial synaptic contacts with lumbosacral motoneurons between 8 and $9 \mathrm{~d}$ of development (stage 32-33; Hamburger and Hamilton, 1951). The goals of the present work were to define the pattern of muscle afferent projections to different lumbosacral motoneurons from day 13 when muscle afferents first reach the lateral motor column until just before hatching (day 19-20), and to characterize the properties of synaptic transmission in more depth. Eide et al. (1982) had provided preliminary evidence that the pattern of connectivity between some muscle afferents and motoneurons is appropriate at hatching, though they focused on the monosynaptic interconnection of synergists and did not systematically analyze the sensorimotor connections between antagonistic muscles. In the present work, we have examined the organization of muscle afferent projections to several flexor and extensor muscles in the thigh, and have introduced a new method for determining the connectivity between muscle afferents and specific pools of motoneurons: recording the electrotonically decremented, afferentevoked synaptic potentials in muscle nerves. This method, which is an extension of the technique for recording synaptic potentials from ventral roots, now enables the detection of subthreshold synaptic potentials in a population of motoneurons innervating a single muscle. 
A

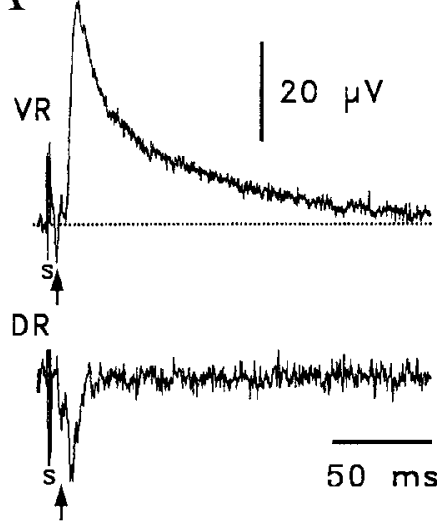

B

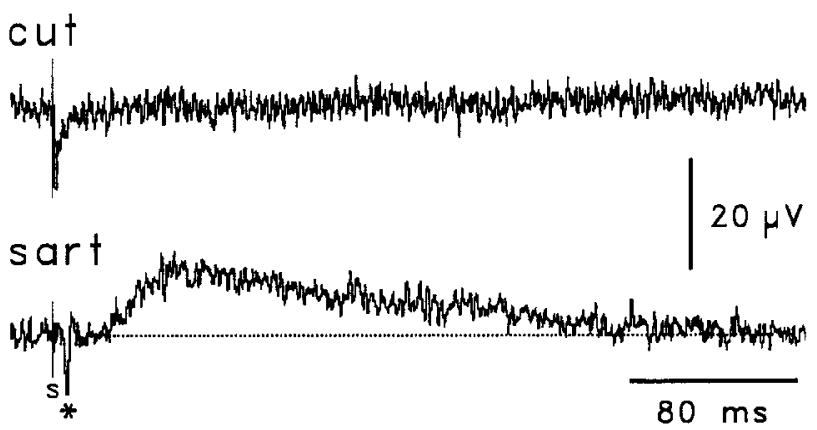

C
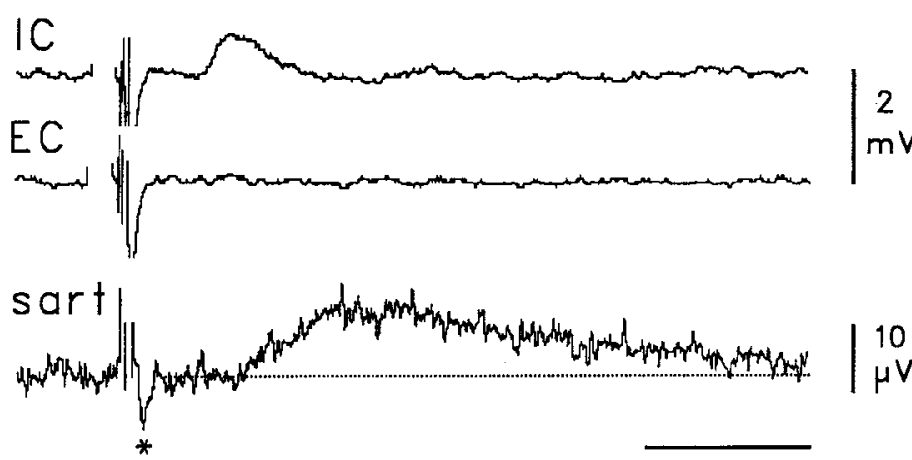

$\mathrm{D}$

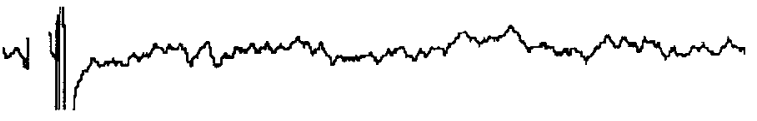

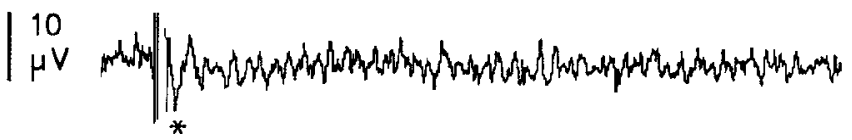

$40 \mathrm{~ms}$

Figure 1. Properties of afferent-evoked muscle nerve potentials recorded in the presence of APV, picrotoxin, and strychnine. $A$ and $B$ provide evidence that afferent-evoked potentials are recorded from motor rather than sensory axons. $A$, Recording from ventral (VR) and dorsal $(D R)$ roots following stimulation of the femorotibialis nerve shows that positive-going potentials were restricted to the ventral root and were not recorded in sensory axons. Following the stimulus artifact $(s)$ was a brief negative deflection (arrow), which was probably the afferent volley. The traces are the average of 10 sweeps and were recorded in a stage 37 embryo. $B$, Comparison of recordings made from the lateral femoral cutaneous nerve (cut) and the sartorius muscle nerve (sart) following stimulation of the adductor nerve reveals that muscle nerve-evoked electrotonic potentials were restricted to muscle nerves. Often the electrotonic potential in the nerve was preceded by a small negative spike (asterisk in $B-D)$, which may represent activation of axons branching down the stimulated and recorded nerve. $C$ and $D$ compare the intracellular potential in a single sartorius motoneuron $(I C)$ and the population potential recorded from the sartorius muscle nerve (sart) recorded in the presence of APV, picrotoxin, and strychnine. $C$, Stimulation of the adductor nerve elicited depolarizing synaptic potentials in the motoneuron and in the muscle nerve. $D$, Perfusion with Tyrode's solution containing 0 calcium and $2 \mathrm{~mm}$ manganese (in addition to APV, picrotoxin, and strychnine) abolished both potentials. The extracellular recording $(E C)$ in $C$ was made after returning to normal Tyrode's solution and withdrawing the electrode from the cell, when the response in the muscle nerve had recovered, and shows that the intracellular record represents the transmembrane potential. Traces in $B-D$ are averages of eight stimuli.

Some of our findings have been published in abstract form (Koebbe and O’Donovan, 1985; Lee and O'Donovan, 1988).

\section{Materials and Methods}

Experiments were performed using White Leghorn chicken embryos obtained from a local supplier (Welp, Inc.) and incubated at $37^{\circ} \mathrm{C}$ in a forced-draft incubator. Embryos were staged according to the criteria of Hamburger and Hamilton (1951). The recordings were made using an isolated preparation of the chick spinal cord that has been reported previously (Lee et al., 1988; O'Donovan, 1989) and will only briefly be described here. The embryo was removed from the egg, rapidly decapitated and eviscerated, and continuously superfused with oxygenated Tyrode's solution. Individual thigh nerves were dissected free and cut close to their junction with the muscle or the skin. The spinal cord was hemisected, removed from the vertebral column with the muscle nerves attached, and pinned onto the Sylgard-lined bottom of a $25 \times 75 \mathrm{~mm}$ Plexiglas chamber. The preparation was continuously perfused $(11 \mathrm{ml}$ $\mathrm{min})$ with oxygenated Tyrode's solution at room temperature $\left(21-24^{\circ} \mathrm{C}\right)$.
The muscle nerves used in this study were the adductor, which is primarily a hip extensor; femorotibialis, a knee extensor; posterior iliotibialis, an extensor of the hip and knee and an external rotator of the hip; sartorius, a hip flexor and knee extensor; iliofibularis, a knee flexor and hip extensor; and anterior iliotibialis, a hip flexor. In some experiments, we also stimulated or recorded from the lateral or medial femoral cutaneous nerve.

Afferents were activated by stimulation of individual nerves. Stimuli were delivered with suction electrodes and consisted of $0.1-0.5-\mathrm{msec}$ square wave pulses of either polarity. Motoneuron responses to muscle nerve stimulation were monitored intracellularly or by recording the electrotonically decremented synaptic potential in the muscle nerve using tight-fitting suction electrodes (O'Donovan, 1987, 1989). The electrotonic population potentials were filtered $(0.1 \mathrm{~Hz}$ to 1 or $5 \mathrm{kHz})$ and usually required averaging to obtain an acceptable signal-to-noise ratio (typically 4-10 sweeps at $1-2 / \mathrm{min}$ to minimize synaptic depression). Potentials obtained in this way from several experiments were averaged together to summarize their time course and average amplitude (O'Donovan, 1989). 


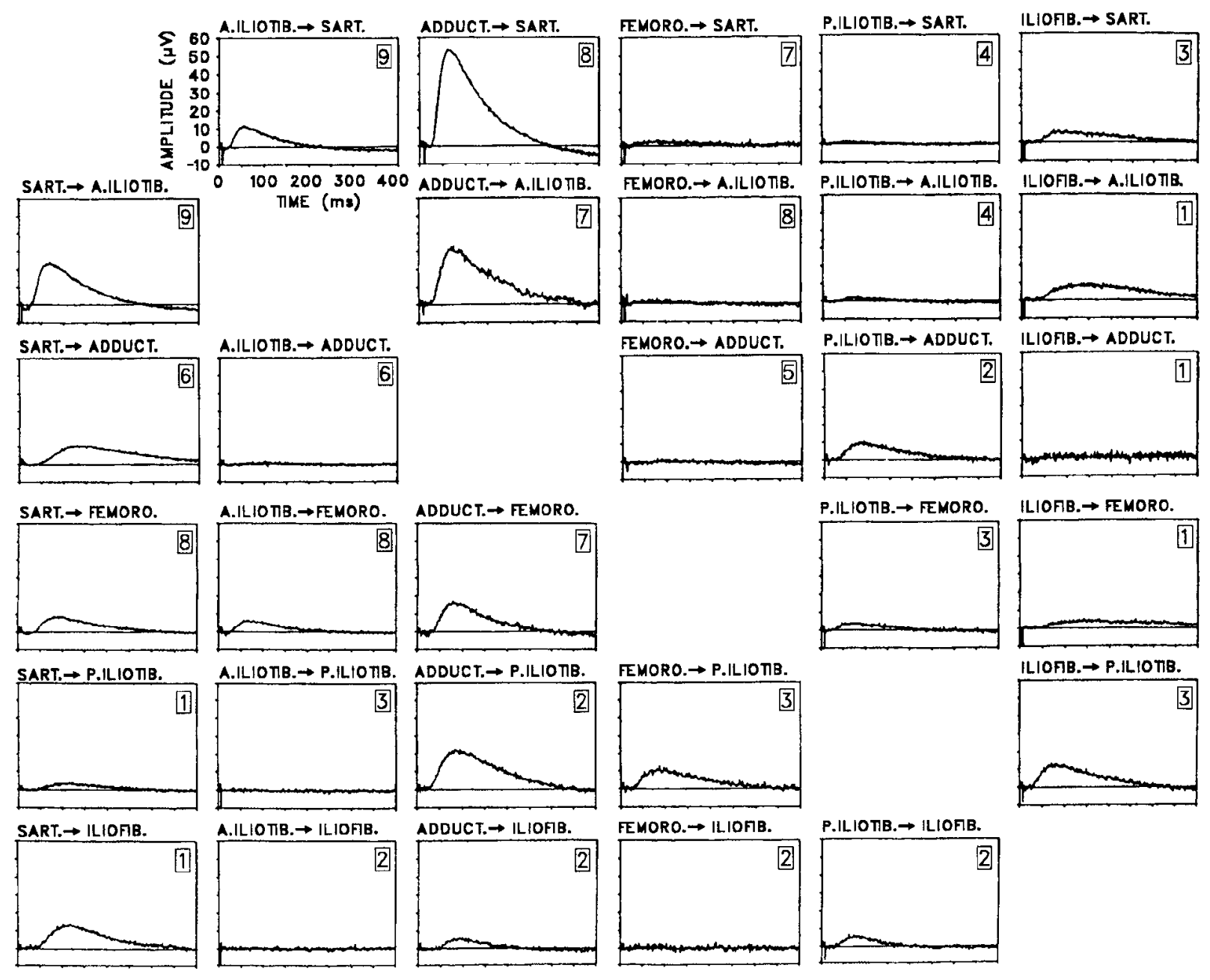

Figure 2. Averaged muscle nerve recordings in stage 37-39 embryos, obtained in response to supramaximal stimulation of other muscle nerves in the presence of bath-applied APV, picrotoxin, and strychnine. Each row displays recordings from a particular muscle nerve, while the columns are arranged according to the nerve that was stimulated. Each recording is the average synaptic potential produced in response to $10-123$ stimuli (4-10 per experiment) in one to nine experiments. Data from 11 experiments have been combined to make the matrix. The diagonal is blank because it was not possible to stimulate and record simultaneously from the same muscle nerve. The number of experiments used for each trace is shown in the box in each plot. SART., sartorius; FEMORO., femorotibialis; $A D D U C T$., adductor; $A$. ILIOTIB., anterior iliotibialis; $P$. ILIOTIB., posterior iliotibialis, ILIOFIB., iliofibularis.

Intracellular recordings from motoneurons were made with glass microelectrodes filled with $2 \mathrm{M}$ potassium citrate and having resistances of 90-130 M . Motoneurons were identified antidromically and by evoking an orthodromically propagated spike in the muscle nerve by intracellular stimulation. A motorized drive (Newport Corp.) was used to advance the microelectrodes into cells. Recordings were accepted only from cells in which the resting membrane potential stabilized at or below $-40 \mathrm{mV}$. Amplified signals were digitized at $10 \mathrm{kHz}$ using a commercially available data acquisition package (Computerscope, RC Electronics, Inc.) run on an IBM XT.

Normal Tyrode's solution had the following composition (in mM): $\mathrm{NaCl}, 139 ; \mathrm{KCl}, 2.9 ; \mathrm{NaHCO}_{3}, 17 ; \mathrm{CaCl}_{2}, 3 ; \mathrm{MgCl}_{2}, 1 ;$ glucose, 12.2 (pH 7.4). In most experiments the bathing medium contained DL-2amino-5-phosphonovaleric acid (APV; $200 \mu \mathrm{M}$; Sigma and Cambridgc Research Biochemicals), picrotoxin (100 $\mu \mathrm{M}$; Sigma), and strychnine (10 $\mu \mathrm{M}$; Sigma) to block long-latency and inhibitory pathways (Lee et al., 1988). High-calcium/high-magnesium Tyrode's contained $12 \mathrm{mM} \mathrm{Ca}$ and $5 \mathrm{mM} \mathrm{Mg}^{2+}$ in addition to APV, picrotoxin, and strychnine; in these solutions, $[\mathrm{NaCl}]$ was reduced to $119.5 \mathrm{~mm}$ to maintain normal osmolarity. Low-calcium solutions contained $0 \mathrm{mM} \mathrm{Ca}^{2+}$ and $2 \mathrm{mM} \mathrm{MnCl}$ in addition to the other constituents.

\section{Results}

Detection of muscle afferent-evoked synaptic potentials in individual muscle nerves

The pattern of connectivity between muscle afferents and various motoneuron pools was assessed using two methods: intracellular recording from single motoneurons and population recordings from muscle nerves. Although population recordings from muscle nerves have been used to detect the slow synaptic potentials associated with rhythmic motor activity (O'Donovan, 1989), they have not previously been used to detect the more rapid mono- and polysynaptic responses evoked by stimulation of muscle afferents. It was necessary, therefore, to show that afferent-evoked potentials recorded from muscle nerves are the result of synaptic activity in the population of motoneurons projecting to a single muscle, and that such recordings can provide a useful monitor of afferent connectivity.

Stimulation of muscle nerves produced long-lasting depolar- 
izations that could be recorded in other muscle nerves. Bath application of a solution containing the amino acid antagonist APV and the inhibitory antagonists picrotoxin and strychnine abolished long-latency components of the muscle nerve potentials, as they do in recordings from the ventral roots and individual motoneurons (Lee et al., 1988). The APV-resistant excitatory potentials originated from motor rather than sensory axons because they could not be recorded from the cut dorsal roots (Fig. $1 A$ ) or from the lateral or medial femoral cutaneous nerves (Fig. $1 B$ ). The muscle nerve potentials were much slower than either ventral root potentials or intracellularly recorded EPSPs (Fig. 1C) and were abolished following superfusion of the cord with low-calcium/high-manganese $\left(0 \mathrm{mM} \mathrm{Ca}^{2+}, 2 \mathrm{~mm}\right.$ $\mathrm{Mn}^{2+}$ ) solutions (Fig. 1D), indicating that they resulted from the action of chemical synapses.

\section{Projection of muscle afferents to lumbosacral motoneurons using muscle nerve recordings in stage 37-39 embryos}

Because muscle nerve recordings were easy to obtain, they allowed the synaptic projections of muscle afferents to be mapped rapidly and conveniently. In Figure 2, the results of this analysis have been presented in a matrix. Each entry in the matrix is the afferent-evoked muscle nerve potential averaged from several experiments. The columns of the matrix compare the projection of a particular muscle nerve to different motoneuron pools, whereas the rows compare the synaptic potentials in the same motoneuron pool following stimulation of different sources. All the recordings were made in the presence of APV, picrotoxin, and strychnine, so that all the connections revealed are excitatory, though not necessarily monosynaptic. The data used to generate the averages are also presented as histograms (Fig. 3), which show the percentage of experiments in which a particular muscle nerve potential could be recorded, which is important in interpreting the amplitude of the averages presented in Figure 2.

The recordings reveal clear differences in the projection patterns of afferents from different muscles. Stimulation of some nerves, such as the sartorius or the adductor, resulted in synaptic potentials in all nerves tested. By contrast, activation of the knee extensor femorotibialis or the anterior and posterior iliotibialis resulted in a more restricted pattern of connections. A striking feature of these results was the presence of excitatory connections between afferents and motoneurons innervating functionally antagonistic muscles (e.g., adductor afferents to sartorius motoneurons). Stimulation of the medial femoral cutaneous muscle nerve also resulted in EPSPs in several muscle nerves revealing the existence of polysynaptic cutaneous projections to motoneurons at stage 37 .

The pattern of connectivity revealed by the muscle nerve recordings was somewhat unexpected and was not simply based on the function (extensor vs. flexor) of the motoneuron pool. Therefore, intracellular recordings were made from individual motoneurons to confirm this pattern of connectivity and to pursue the properties of the connections in more detail.

\section{Pattern of sensorimotor connections revealed by intracellular recording}

Intracellular recordings were obtained from 64 identified motoneurons: two sets of hip flexor motoneurons, sartorius ( $n=$ 13) and anterior iliotibialis $(n=9)$, and one knee extensor, femorotibialis $(n=42)$. Motoneurons were identified by antidromic firing and by recording the orthodromically propagated

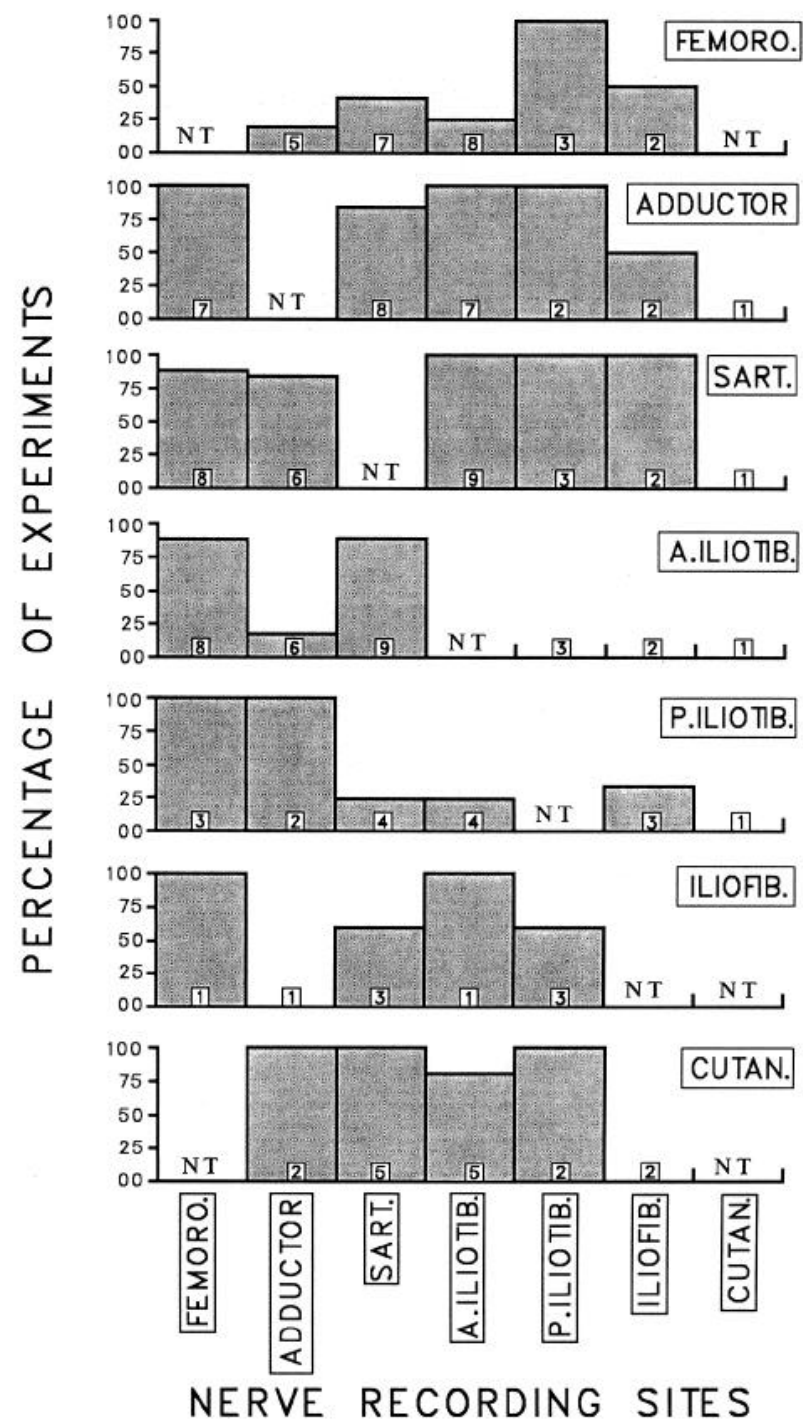

Figure 3. Summary of the frequency of occurrence of synaptic potentials in six different muscle nerves (abbreviated as in Fig. 2) and in one cutaneous nerve (CUTAN.) following stimulation of those nerves in stage 37-39 embryos. Data were obtained from the same 11 experiments used to make Figure 2. The number of experiments in which each nervenerve pair was tested is indicated within the bar for that pair. The absence of data in the diagonal is because it was not possible to record from the stimulated nerve. The occurrence of a synaptic potential was defined as a persistent, positive deviation from a flat baseline in the averaged record for that particular experiment. $N T$, not tested.

spike in the muscle nerve following intracellular stimulation (Fig. 4). Twenty-four of the motoneurons were impaled in stage 37-39 embryos, the age at which muscle nerve recordings were made. This is about the same stage at which muscle afferents reach the lateral motor column in substantial numbers (Lee et al., 1988; Davis et al., 1989). The remaining 40 motoneurons were impaled at stage $44,1-2 \mathrm{~d}$ before hatching. In most cases ( $n=44)$, recordings were made in the presence of APV, picrotoxin, and strychnine to isolate excitatory connections; we have also included four recordings obtained in the presence of APV alone and 14 made in the absence of any pharmacological agents.

The pattern of connectivity revealed by intracellular recording was similar to that obtained from the muscle nerves. Repre- 
FEMORO. MOTONEURON
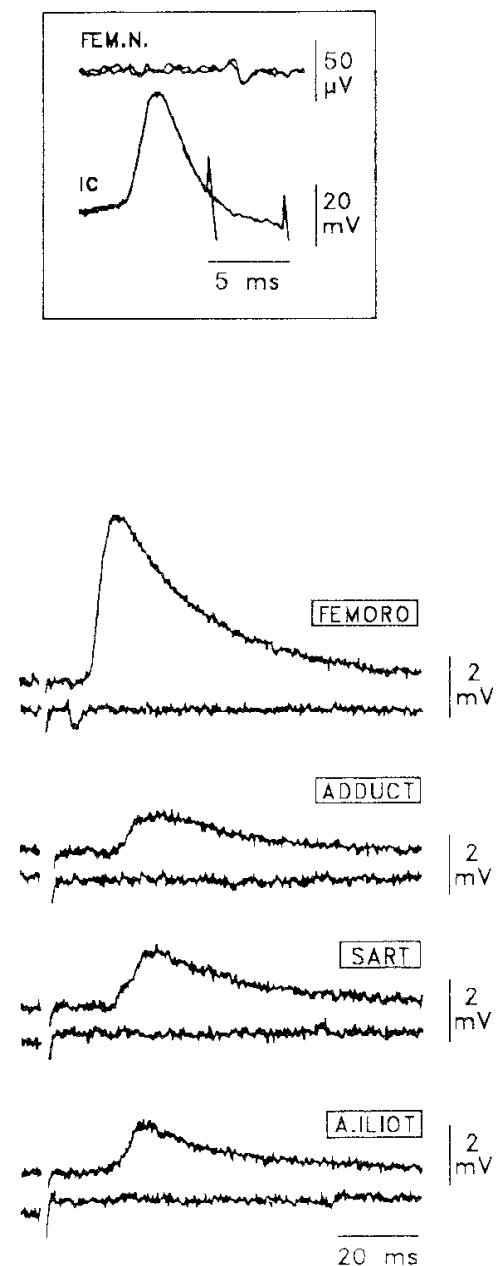

SARTORIUS MOTONEURON
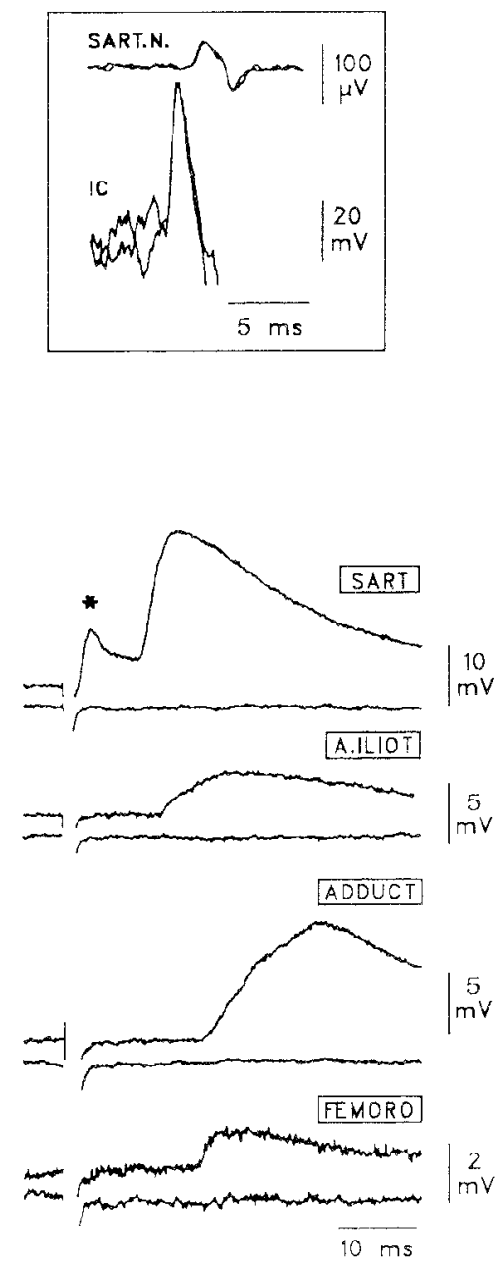

A. ILIOTIB. MOTONEURON

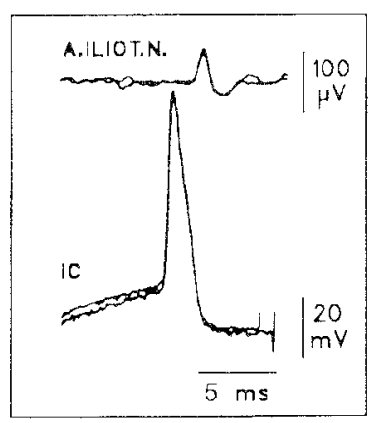

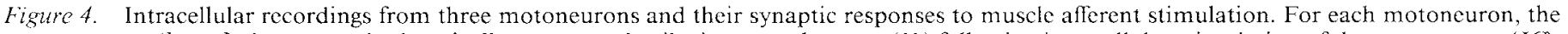

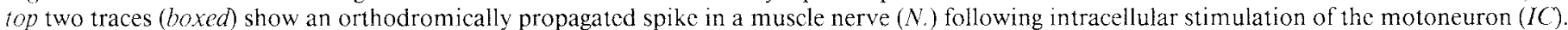

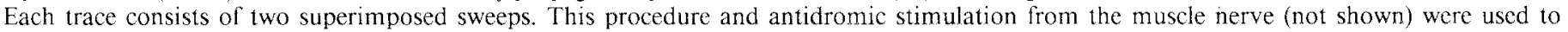

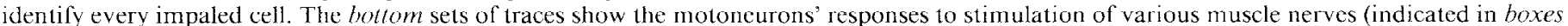

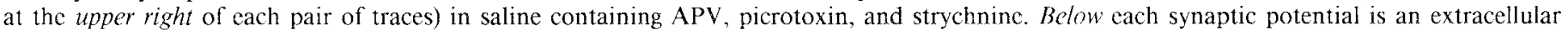

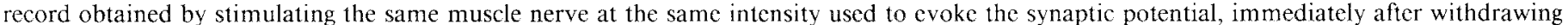

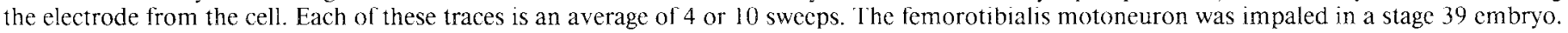

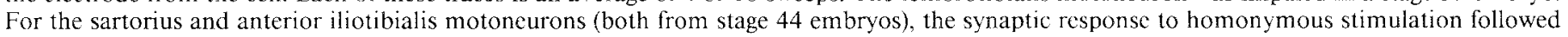
the antidromic initial segment spike (*). Muscle abbreviations are as in Figure 2.

sentative records from three motoneurons are illustrated in Figure 4 , and a summary of the synaptic inputs to all of the motoneurons is presented in Figure 5. All motoneurons received input from afferents in the homonymous muscle nerve, and the resulting EPSP was generally larger than the EPSPS generated from other sources of stimulation. Homonymous EPSPs of approximately $20 \mathrm{mV}$ were recorded, though the maximum amplitude of these EPSPs could not always be ascertained, because the threshold of the afferents evoking the EPSP was often similar to that of the motor axon.

In most motoneurons, FPSPs were also recorded following stimulation of either synergist or antagonist muscle nerves. Nearly all of the sartorius and anterior iliotibialis motoneurons received input from femorotibialis or adductor muscle afferents (or both), as well as their respective homonymous and synergist inputs. Similarly, half of the femorotibialis motoneurons were excited by afferents in one or both of the sartorius and anterior iliotibialis nerves.

While some of the postsynaptic potentials (PSPs) had relatively simple shapes, others clearly had multiple components, even in saline containing APV, picrotoxin, and strychnine (Fig. 4). These compound PSPs generally had longer latencies, suggesting that they were produced via polysynaptic pathways.

\section{Latency differences of afferent-cvoked EPSPS}

The latency from the stimulus to the onset of afferent-evoked synaptic potentials was measured for femorotibialis, sartorius, and anterior iliotibialis motoneurons at stages 37-39 and 44 (Fig. 5). In general, latencies from all sources were slightly shorter at stage 44 , despite the somewhat greater nerve lengths at this stage. This decrease in latency during development may result from a rise in afferent conduction velocity. 

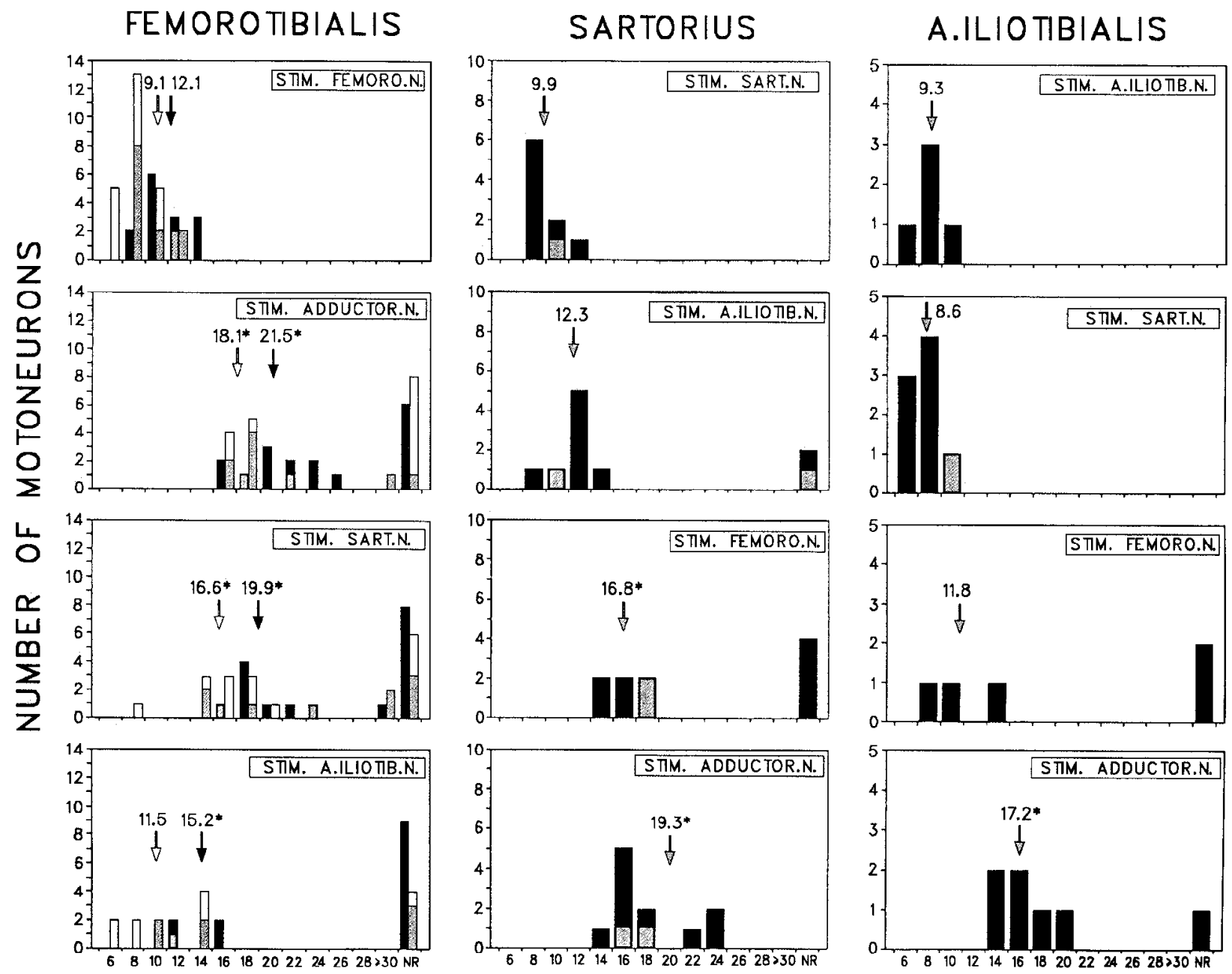

LATENCY OF SYNAPTIC POTENTIAL (ms)

Figure 5. Latency histograms of the intracellularly recorded postsynaptic potentials. The muscle nerve $(N$.$) that was stimulated (S T I M$.) to produce the EPSPs is indicated in the boxed region at the upper right of cach histogram. Recordings obtained from femorofibialis motoneurons at stages 37-39 are represented by solid bars, while open bars pertain to recordings from stage 44 embryos. The data from the two ages have been combined in the sartorius and a. iliotibialis histograms. EPSPs recorded in normal Tyrode's solution or in the presence of APV are designated by shaded bars; all other recordings were made in Tyrode's solution containing APV, picrotoxin, and strychnine. For femorotibialis motoneurons, the mean latencies at stages 37-39 and 44 are indicated by solid and open arrows, respectively, and are shown above the respective arrows. For sartorius and anterior iliotibialis motoneurons, mean latencies were calculated for all stages combined and are indicated by the shaded arrows. An asterisk beside the latency indicates that the mean latency of the EPSP in a particular set of motoneurons was significantly different from the latency of the homonymous EPSP in the same set of motoneurons at the same stage. $N R$, no response, defined as a flat baseline in the averaged intracellular record. Muscle abbreviations are as in Figure 2.

To compare quantitatively the latencies of synaptic potentials from various sources, the mean latency of EPSPs produced by each type of afferent was calculated for each class of motoneuron. Only EPSPs with latencies of less than $30 \mathrm{msec}$ were included in this calculation (this criterion excluded only $3 \%$ of the synaptic inputs). The mean latencies are indicated by arrows in the histograms of Figure 5. The significance of differences in latency (for a particular muscle nerve vs. the homonymous nerve) was assessed with the Student's $t$ test $(p=0.05)$.

For femorotibialis motoneurons, the latency of the homonymous EPSP at stages 37-39 was significantly shorter than the latencies of EPSPs produced by stimulation of the adductor, sartorius, and anterior iliotibialis nerves at those stages. At stage 44, the homonymous EPSP latency was also significantly shorter than the latencies of adductor and sartorius inputs, but was not significantly different from the latency of the EPSP resulting from anterior iliotibialis nerve stimulation.
For sartorius and antcrior iliotibialis motoncurons, too few recordings were made at stages $37-39$ to permit a statistical analysis of latency differences among the various afferent sources at those stages. Therefore, latency measurements were combined for all stages for these motoneurons. For both groups of motoneurons, the homonymous and synergist EPSPs had latencies that were not statistically different. In addition, femorotibialis afferents produced EPSPs in anterior iliotibialis motoneurons at latencies that overlapped those of the homonymous inputs.

These results corroborate the muscle nerve recordings and reveal that motoneurons receive excitatory inputs from several sources. The latency measurements showed that the connections fell into two groups: one set of connections whose latency was similar to that of the homonymous EPSP, and a second set with distinctly longer latencies. These differences were not simply attributable to differences in conduction time because the latencies for the homonymous EPSPs for each class of motoneu- 

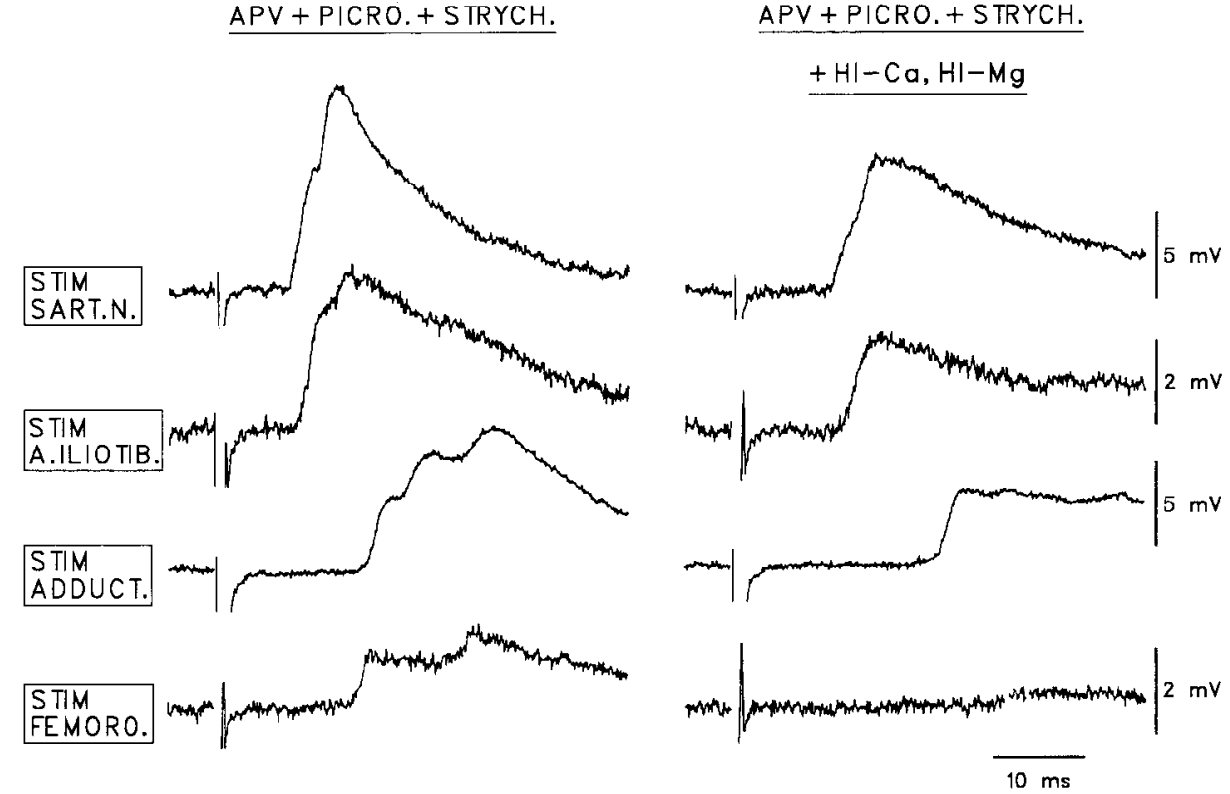

Figure 6. Effects of high-divalent-ion solution on EPSPs generated in a sartorius motoneuron by stimulation of various muscle nerves. In APV, picrotoxin, and strychnine (left), short-latency EPSPs were produced by afferents in the homonymous and synergist (anterior iliotibialis) nerves, and long-latency EPSPs were produced by afferents in two antagonist nerves (adductor and femorotibialis). In saline containing 12 $\mathrm{mM} \mathrm{Ca}^{2+}$ and $5 \mathrm{mM} \mathrm{Mg}^{2+}$ plus the same pharmacological blockers (right), only the femorotibialis EPSP was largely abolished; the other three synaptic potentials persisted, though with longer latencies. Each trace is an average of 4 or 10 sweeps from a stage 44 embryo. Muscle abbreviations are as in Figure 2 .

ron (sartorius, anterior iliotibialis, and femorotibialis) were all similar (Fig. 5). The short-latency connections include reciprocal contacts between afferents and motoneurons innervating the femorotibialis, a knee extensor, and the anterior iliotibialis, a hip flexor.

\section{Differential effects of high-divalent-ion solutions and repetitive stimulation on short-and long-latency potentials}

To establish whether any of the connections we detected were monosynaptic, two additional tcsts werc cmployed. In the first of these, the preparation was bathed in a solution containing high concentrations of calcium and magnesium ions (12 and 5 $\mathrm{mM}$, respectively). Such solutions have been used to distinguish between mono- and polysynaptic connections in other species (Berry and Pentreath, 1976; Jahr and Yoshioka, 1986) and are thought to raise spike thresholds (Frankenhaeuser and Hodgkin, 1957), thereby compromising transmission through polysynaptic pathways. This procedure was employed on eight motoneurons (four sartorius, two anterior iliotibialis, and two femorotibialis). For each cell, the homonymous, one synergist, and two antagonist nerves were tested for input to the cell. In all eight motoneurons, the homonymous EPSP persisted in high-calcium/high-magnesium saline, though sometimes its amplitude was reduced (Fig. 6). The effects of the high-calcium and -magnesium solutions on the nonhomonymous inputs were more variable. In two motoneurons, the homonymous EPSP persisted while other synergist and antagonist PSPs were suppressed. The homonymous and synergist EPSP persisted in one of the remaining motoneurons, but in five other motoneurons both synergist and antagonist PSPs could still be detected in the highdivalent solutions (Fig. 6). In general, there was an increase in the latencies of all of the PSPs that persisted in this saline.

The application of high divalent ions did not produce an unambiguous separation of the projections into distinct classes corresponding to mono- and polysynaptic populations. In all the motoneurons we tested, the homonymous EPSP remained in the presence of high concentrations of divalent ions, suggesting it was monosynaptic, but the situation for the other inputs was not as clear. For this reason, we examined the ability of the afferent-evoked PSPs to follow repetitive stimulation (at $5 \mathrm{~Hz}$ ), which is another test used to distinguish mono- from polysynaptic pathways (Berry and Pentreath, 1976). The test
Figure 7. Effects of repetitive stimulation on EPSPs generated in a sartorius motoneuron by homonymous, synergist, and antagonist muscle afferents. The three panels show the cell's responses to stimulating a particular afferent source with a train of eight stimuli at $5 \mathrm{~Hz}$. The response to the first stimulus is at the top. Each panel is an average of 10 trains repeated at 1 train/ min. Both the homonymous and the synergist EPSPs followed the stimuli one for one, whereas the antagonist EPSP was eliminated after the first stimulus. The recordings were taken from a stage 44 embryo in high-calcium/high-magnesium saline containing APV, picrotoxin, and strychnine. Muscle abbreviations are as in Figure 2.

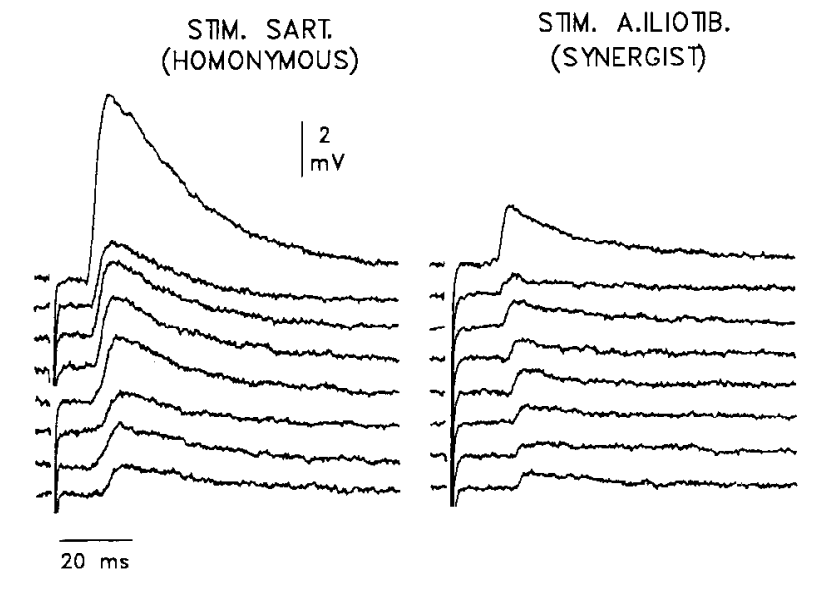

STIM. A.ILIOTIB. (SYNERGIST)

STM. ADDUCT. (ANTAGONIST)

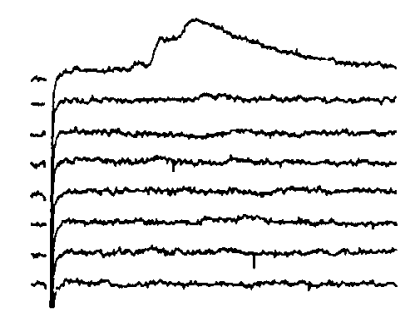


was performed in one femorotibialis and three sartorius motoneurons, and the results from one of the sartorius motoneurons are shown in Figure 7. In this cell, the short-latency homonymous and synergist EPSPs persisted throughout the stimulation, with a progressive decline in amplitude and a slight increase in latency. In contrast, the long-latency antagonist EPSP disappeared after the first stimulus at this frequency. Similar findings were obtained for the other two sartorius motoneurons, suggesting that the short-latency EPSPs were produced monosynaptically, whereas the longer-latency potentials were mediated via polysynaptic pathways. In the femorotibialis motoneuron, the homonymous input persisted at $5 \mathrm{~Hz}$, but EPSPs resulting from stimulation of anterior iliotibialis and adductor nerves failed, suggesting that they originated polysynaptically.

It might be argued that these tests might, in principle, be compromised by the immaturity of the developing synapses in the embryonic cord. Although synaptic depression of the shortlatency EPSPs was more severe than in intact, adult preparations, the test separated the connections in two groups that correlated with their latency. It seems unlikely, therefore, that this association is fortuitous and simply a result of the immaturity of the connections.

\section{Discussion}

This article has analyzed the excitatory synaptic projections of thigh muscle afferents to several classes of lumbar motoneurons between days 13 and 20 in the chick embryo. The majority of projections were examined after blockade of inhibitory connections and excitatory synapses mediated by NMDA receptors, and therefore represent the mono- and polysynaptic projections mediated by non-NMDA receptors. Our results, which are summarized in Figure 8, indicate that the excitatory synaptic connections of afferents from individual muscles can be widespread, projecting to several flexor and extensor motoneurons pools, though the monosynaptic connections follow the pattern established in studies of several other species (see below).

\section{Distribution of monosynaptic connections between muscle afferents and motoneurons}

Studies of the monosynaptic projections of muscle spindle afferents in adult animals have shown that anatomically synergistic muscles or those that are functionally related in locomotion (Eccles et al., 1957a; Eccles and Lundberg, 1958; Engberg and Lundberg, 1969; Frank and Westerfield, 1982; Fritz et al., 1989) share monosynaptic connections from muscle afferents. The monosynaptic connections found in the present study conform to these principles and are consistent with preliminary investigations of sensorimotor connectivity in the chick embryo carried out by Eide et al. (1982).

The only short-latency, presumably monosynaptic connections we found were between the synergistic hip flexors sartorius and anterior iliotibialis, and between the anterior iliotibialis and the femorotibialis. The latter pair of muscles are not anatomical synergists because the femorotibialis functions as a knee extensor. However, both muscles are active in late swing during walking, and it has been suggested that the anterior iliotibialis activity supplements the action of femorotibialis in moving the lower limb forward in preparation for footfall (Jacobson and Hollyday, 1982). It is interesting to note that the cat rectus femoris and vasti, muscles that are homologous to the chick anterior iliotibialis and femorotibialis (Lance-Jones, 1979), also share reciprocal monosynaptic connections (Eccles and Lundberg, 1958).

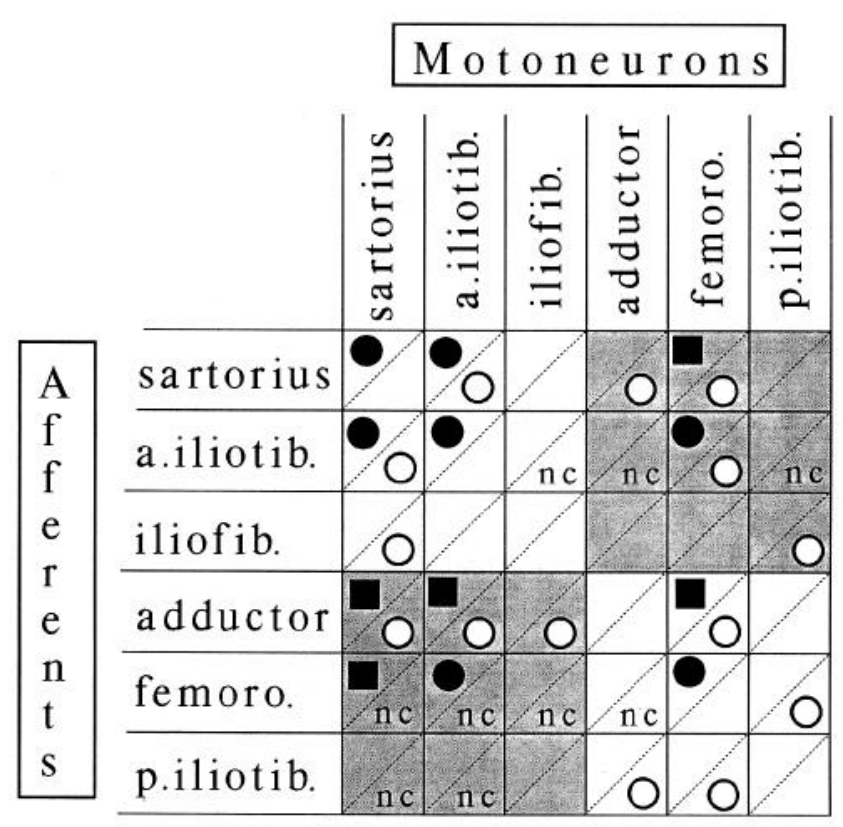

$$
\begin{aligned}
& \text { nc no connection muscle nerve } \\
& \text { O connection }\} \text { recording } \\
& \left.\begin{array}{l}
\text { polysynaptic } \\
\text { monosynaptic }
\end{array}\right\} \begin{array}{c}
\text { intracellular } \\
\text { recording }
\end{array}
\end{aligned}
$$

Figure 8. Summary of the connections between muscle afferents and motoneurons determined using intracellular and muscle nerve recordings. The rows indicate the muscle afferents that were stimulated, whereas the motoneuron or muscle nerve that was recorded from is shown in the columns. Monosynaptic connections (solid circles) are defined as homonymous EPSPs and other synaptic potentials whose latency overlapped that of the homonymous EPSP. Exclusively polysynaptic connections (solid squares) are all other connections recorded intracellularly with a latency $<30 \mathrm{msec}$. Connections detected by muscle nerve recordings (open circles) are not differentiated as mono- or polysynaptic. Positive connections were defined as those in which the averaged muscle nerve potential was $\geq 5 \mu \mathrm{V}$ and the projection frequency was $>50 \%$. No connection $(n c)$ was defined as an averaged muscle nerve potential $<5 \mu \mathrm{V}$ and a projection frequency $\leq 50 \%$. All but two connections could be categorized in this way. Cells with no entry indicate that connection was not tested. The shaded and unshaded regions differentiate two classes of afferent-motoneuron connections. The unshaded regions show homonymous or synergistic connections, while the shaded regions define largely antagonistic connections. Muscle abbreviations are as in Figure 2 .

While these observations strongly suggest that the monosynaptic connections we have detected in the embryo reflect the mature pattern, we cannot be certain that they are completely normal until comparable recordings have been made in adult animals.

The first monosynaptic connections between lumbosacral motoneurons and femorotibialis afferents form at about stages 32-33 (Lee et al., 1988), though at these stages there are probably very few direct contacts, because HRP-labeled primary afferent axons are largely restricted to the dorsal horn (Lee et al., 1988; Davis et al., 1989). The earliest stages at which sensorimotor connections were studied in the present investigation were stages $37-39$, and only femorotibialis motoneurons were impaled in sufficient numbers at these stages to analyze the pattern of mono- 
synaptic connections. We found no change in the pattern of inputs to these motoneurons at stage 44 , suggesting few, if any, inappropriate connections at stage 37-39. Most of the recordings from sartorius and anterior iliotibialis motoneurons were obtained just prior to hatching (at stage 44), and information about the early pattern of connectivity onto these motoneurons is inadequate. In order to determine whether the earliest sensorimotor connections are inappropriate in the chick, additional recordings will have to be made in younger animals.

In the present work, we have focused on the muscle afferent connections mediated by non-NMDA receptors, raising the possibility that we might have missed a class of monosynaptic connections mediated exclusively (or predominantly) by NMDA receptors. There is, however, no evidence for a class of muscle afferents that utilizes NMDA receptors exclusively. Instead, the evidence suggests that single muscle afferents release a transmitter acting on both NMDA and non-NMDA receptors (Ziskind-Conhaim, 1990). Activation of non-NMDA and NMDA receptors has also been demonstrated for interneuron-motoneuron synapses in the lamprey (Dale and Grillner, 1986) and in the frog embryo (Dale and Roberts, 1985), so it may be a general property of excitatory amino acid-mediated synaptic transmission. Although it is not clear whether the monosynaptic EPSP in the chick also includes an NMDA receptor-activated component (Lee et al., 1988), the pattern of monosynaptic connections detected in the presence and absence of APV should be similar, assuming that single muscle afferents activate both receptor classes.

\section{Synaptic depression in the monosynaptic pathway}

A prominent feature of transmission in the monosynaptic pathway was a substantial depression in the amplitude of the monosynaptic EPSP during low rates of stimulation, confirming earlier studies by Kudo and Yamada (1985) in the rat fetus. The depression of the EPSP is not due to a failure of spike invasion of the afferent terminals, because the presynaptic spike (see Lee et al., 1988) is unaffected at these frequencies of stimulation (M. Koebbe and M. J. O’Donovan, unpublished observations). Synaptic depression can be detected at adult Ia synapses, but it tends to be dominated by posttetanic potentiation (Lev-Tov et al., 1983, 1988). In adult systems, synaptic depression of Ia EPSPs is thought to be due to a reduced probability of transmitter release at synaptic endings (Lev-Tov et al., 1983). Using the isolated cord preparation, it should be possible to establish whether or not the depression we have observed in immature muscle afferent synapses is the result of a similar mechanism.

\section{Distribution of polysynaptic excitatory connections between muscle afferents and motoneurons}

Long-latency, fatiguable PSPs could be evoked in motoneurons in response to activation of muscle afferents. Such potentials are presumably mediated by polysynaptic pathways between motoneurons and muscle afferents. The distribution of these projections did not conform to any particular pattern (see Fig. 8), presumably because several classes of muscle afferent were activated by the sensory nerve stimulus. While we attempted to limit the expression of polysynaptic responses in motoneurons by bath application of APV (Jahr and Yoshioka, 1986), it was clear that some polysynaptic excitatory projections persisted in this saline. This result indicates that polysynaptic pathways are capable of activating both NMDA and non-NMDA recep- tors, though from the present results we cannot be sure that both receptor classes are activated by the same pathway.

One possibility is that the sensory stimulus activated tendon organ afferents, assuming they are present in chick muscle nerves, in addition to those innervating muscle spindles. In adult cats, the electrical thresholds of tendon organ afferents are similar to those of muscle spindle afferents (Bradley and Eccles, 1953). Because tendon organ afferents project polysynaptic excitation to antagonist motoneurons (Laporte and Lloyd, 1952; Eccles et al., 1957b), their activation could account for the excitatory connections we have observed.

\section{Organization of muscle afferent projections according to the developmental history of the muscle they innervate}

The monosynaptic connections we found were all between afferents from muscles with a similar embryological origin, though muscles with a similar developmental history did not necessarily share monosynaptic connections. The sartorius and anterior iliotibialis shared the strongest bidirectional monosynaptic connections, and these muscles are derived from the superficial dorsal muscle mass (Lance-Jones, 1979). Weaker monosynaptic connections were also detected between the anterior iliotibialis and the femorotibialis, which is also derived from the superficial dorsal muscle mass. In contrast, we did not detect monosynaptic connections between sartorius and femorotibialis motoneurons, though the sample was small and we may have missed such connections. These relationships are of interest because they appear to be preserved in the homologous muscles of the cat even though the function of these muscles presumably differs between the quadrupedal cat and the bipedal chick (Eccles and Lundberg, 1958). More comprehensive studies of muscle afferent connectivity will be necessary to establish whether or not this correlation is merely coincidental (reflecting the proximity of the muscles in the limb) or reflects a mechanism for specifying the central projections of muscle afferents based upon some shared quality of the muscle they innervate (cf. Frank and Westerfield, 1983).

\section{References}

Berry MS, Pentreath VW (1976) Criteria for distinguishing between monosynaptic and polysynaptic transmission. Brain Res 105:1-20.

Bradley K, Eccles JC (1953) Analysis of the fast afferent impulses from thigh muscles. J Physiol (Lond) 122:462-473.

Dale N, Grillner S (1986) Dual-component synaptic potentials in the lamprey mediated by excitatory amino acid receptors. J Neurosci 6 : 2653-2661.

Dale N, Roberts A (1985) Dual-component amino-acid-mediated synaptic potentials: excitatory drive for swimming in Xenopus embryos. J Physiol (Lond) 363:35-59.

Davis BM, Frank E, Johnson FA, Scott SA (1989) Development of central projection of lumbosacral sensory neurons in the chick. J Comp Neurol 279:556-566.

Eccles JC, Eccles RM, Lundberg A (1957a) The convergence of monosynaptic excitatory afferents on to many different species of alpha motoneurones. J Physiol (Lond) 137:22-50.

Eccles JC, Eccles RM, Lundberg A (1957b) Synaptic actions on motoneurones caused by impulses on Golgi tendon organ afferents. $J$ Physiol (Lond) 138:227-252.

Eccles RM, Lundberg A (1958) Integrative patterns of Ia synaptic actions of motoneurones of hip and knee muscles. J Physiol (Lond) 144:271-298.

Eide AH, Jansen JKS, Ribchester RR (1982) The effect of lesions in the neural crest on the formation of synaptic connexions in the embryonic chick spinal cord. J Physiol (Lond) 324:453-478.

Engberg I, Lundberg A (1969) An clcctromyographic analysis of muscular activity in the hindlimb of the cat during unrestrained locomotion. Acta Physiol Scand 75:614-630. 
Frank E, Westerfield M (1982) Synaptic organization of sensory and motor neurones innervating triceps brachii muscles in the bullfrog. $J$ Physiol (Lond) 324:479-494.

Frank E, Westerficld M (1983) Development of sensory-motor synapses in the spinal cord of the frog. J Physiol (Lond) 343:593-610.

Frankenhaeuser B, Hodgkin AL (1957) The action of calcium on the electrical properties of squid axons. J Physiol (Lond) 137:218-244.

Fritz N, Illert M, de la Motte S, Reeh P, Saggau P (1989) Pattern of monosynaptic 1a connections in the cat forelimb. J Physiol (Lond) 419:321-351.

Hamburger V (1976) The developmental history of the motor neuron. Neurosci Res Prog Bull 15:1-37.

Hamburger V, Hamilton HL (1951) A series of normal stages in the development of the chick embryo. J Morphol 88:49-92.

Honig MG (1982) The development of sensory projection patterns in embryonic chick hind limb. J Physiol (Lond) 330:175-202.

Jacobson RD, Hollyday M (1982) A behavioral and electromyographic study of walking in the chick. J Neurophysiol 48:238-256.

Jahr CE, Yoshioka K (1986) Ia afferent excitation of motoneurones in the in vitro new-born rat spinal cord is selectively antagonized by kynurenate. J Physiol (Lond) 370:515-530.

Koebbe M, O'Donovan MJ (1985) Properties and distribution of muscle afferent projections to lumbosacral motoneurons in the spinal cord of the chick embryo. Soc Neurosci Abstr 11:63.

Kudo N, Yamada T (1985) Development of the monosynaptic stretch reflex in the rat: an in vitro study. J Physiol (Lond) 369:127-144.

Lance-Jones C (1979) The morphogenesis of the thigh of the mouse with special reference to tetrapod muscle homologies. J Morphol 162: 275-309.

Lance-Jones C, Landmesser L (1981) Pathway selection by embryonic chick motoneurons in an experimentally altered environment. Proc R Soc Lond [Biol] 214:19-52.

Landmesser LT, O'Donovan MJ (1984) The activation patterns of embryonic chick motoneurones projecting to inappropriate muscles. J Physiol (Lond) 347:205-224.

Laporte Y, Lloyd DPC (1952) Nature and significance of the reflex connections established by large afferent fibers of muscular origin. Am J Physiol 169:609-621.
Lee MT, O'Donovan MJ (1988) Excitatory sensorimotor connections between antagonists in the isolated chick embryo spinal cord. Soc Neurosci Abstr 14:579.

Lee MT, Koebbe MJ, O'Donovan MJ (1988) The development of sensorimotor synaptic connections in the lumbosacral spinal cord of the chick embryo. J Neurosci 8:2530-2543.

Lev-Tov A, Pinter MJ, Burke RE (1983) Posttetanic potentiation of group la EPSPs: possible mechanisms for differential distribution among medical gastrocnemius motoneurons. J Neurophysiol 50:379398.

Lev-Tov A, Meyers DER, Burke RE (1988) Activation of type B $\gamma$-aminobutyric acid receptors in the intact mammalian spinal cord mimics the effects of reduced presynaptic $\mathrm{Ca}^{2+}$ influx. Proc Natl Acad Sci USA 85:5330-5334.

O'Donovan MJ (1987) Developmental approaches to the analysis of vertebrate central pattern generators. J Neurosci Methods 21:275286.

O'Donovan MJ (1989) Motor activity in the isolated spinal cord of the chick embryo: synaptic drive and firing pattern of single motoneurons. J Neurosci 9:943-958.

Okado N, Oppenheim RW (1985) The onset and development of descending pathways to the spinal cord in the chick embryo. J Comp Neurol 232:143-161.

Scott SA (1982) The development of the segmental pattern of skin sensory innervation patterns in the embryonic chick hindlimb. J Physiol (Lond) 330:203-220.

Windle WF, Baxter RE (1936) Development of reflex mechanisms in the spinal cord of albino rat embryos. Correlations between structure and function and comparisons between the cat and the chick. J Comp Neurol 63:189-209.

Windle WF, Orr DW (1934) The development of behavior in chick embryos: spinal cord structure correlated with early somatic motility. J Comp Neurol 60:287-307.

Ziskind-Conhaim L (1990) NMDA receptors mediate poly- and monusynaptic potentials in motoneurons of rat embryos. $J$ Neurosci $10: 125-135$. 